\title{
ABSOLUTE CONFIGURATION and BIOLOGICAL PROFILE of PYRAZOLINE ENANTIOMERS aS MAO INHIBITORY ACTIVITY
}

\author{
Umut Salgin Goksen ${ }^{[a, b]}$, Sevgi Sarıgul ${ }^{[c]}$, Patrick Bultinck ${ }^{[d]}$, Wouter Herrebout ${ }^{[e]}$, Ilknur \\ Dogan $^{[c]}$, Kemal Yelekci ${ }^{[f]}$, Gulberk Ucar ${ }^{[g]}$, Nesrin Gokhan Kelekci* ${ }^{*[a]}$ \\ ${ }^{a}$ Department of Pharmaceutical Chemistry, Faculty of Pharmacy, Hacettepe University, \\ 06100 Sıhhiye, Ankara, Turkey. \\ ${ }^{\mathrm{b}}$ Turkish Medicines and Medical Devices Agency, Analyses and Control Laboratories, \\ 06100, Ankara, Turkey. \\ ${ }^{c}$ Chemistry Department, Bogazici University, Bebek, 34342 Istanbul, Turkey. \\ ${ }^{d}$ Department of Chemistry, Ghent University, Krijgslaan 281, S3, 9000 Gent, Belgium. \\ ${ }^{e}$ Department of Chemistry, University of Antwerp, Groenenborgerlaan 171, 2020 Antwerp, \\ Belgium. \\ ${ }^{f}$ Department of Bioinformatics and Genetics, Faculty of Engineering and Natural Sciences, \\ Kadir Has University, 34083 Fatih, Istanbul, Turkey. \\ ${ }^{9}$ Department of Biochemistry, Faculty of Pharmacy, Hacettepe University, 06100 Sıhhiye, \\ Ankara, Turkey. \\ ${ }^{*}$ Corresponding author: \\ Nesrin Gokhan Kelekci \\ e-mail: onesrin@gmail.com,onesrin@hacettepe.edu.tr
}




\section{Abstract}

A new racemic pyrazoline derivative was synthesized and resolved to its enantiomers using analytic and semipreparative high pressure liquid chromatography (HPLC). The absolute configuration of both fractions was established using Vibrational Circular Dichroism (VCD). The in vitro monoamine oxidase (MAO) inhibitory profiles were evaluated for the racemate and both enantiomers separately for the two isoforms of the enzyme. The racemic compound and both enantiomers were found to inhibit hMAO-A selectively and competitively. In particular, the $R$ enantiomer was detected as an exceptionally potent and a selective MAO-A inhibitor $\left(\mathrm{K}_{\mathrm{i}}=0.85 \times 10^{-3} \pm 0.05 \times 10^{-3} \mu \mathrm{M}\right.$ and $\left.\mathrm{SI}: 2.35 \times 10^{-5}\right)$ whereas $\mathrm{S}$ was determined as poorer compound than $R$ in terms of $\mathrm{Ki}$ and $\mathrm{SI}(0.184 \pm 0.007$ and 0.001$)$.

The selectivity of the enantiomers was explained by molecular modeling docking studies based on the PDB enzymatic models of MAO isoforms.

Keywords: 2-Pyrazoline, Stereochemistry, Vibrational Circular Dichroism, Specific rotation, Monoamine Oxidase Inhibitory Activity, Molecular Modelling Docking

\section{INTRODUCTION}

Monoamine oxidase (MAO) is a flavin adenine dinucleotide (FAD)-containing enzyme which is located in the outer mitochondrial membranes of neuronal, glial and other cells.[1,2] It catalyzes the oxidative deamination of biogenic amines in the brain [3] and the peripheral tissues, regulating their level. [4], MAO exists in two forms, MAO-A and MAO-B. [4] MAO-A catalyzes the oxidative deamination of serotonin (5-HT), adrenaline $(A)$, and noradrenaline (NA) and is selectively inhibited by the irreversible inhibitor clorgyline and the reversible inhibitor moclobemide. MAO-B catalyzes the oxidative deamination of phenylethylamine and benzylamine and is selectively inhibited by the irreversible inhibitor selegiline. $[4,5]$

MAO-A and MAO-B play essential roles in vital physiological processes and are involved in the pathogenesis of various diseases in human. [6,7] Due to their key role, MAO inhibitors represent a useful tool for the treatment of several psychiatric and neurological diseases. In particular, reversible and selective MAO-A inhibitors are used as antidepressant and antianxiety drugs, while MAO-B inhibitors have been found to be useful as coadjuvants in the treatment of Parkinson's disease (PD) and Alzheimer's disease (AD). [8-15]

The development of MAO inhibitors started with hydrazine derivatives. However, they were withdrawn due to their toxic side effects. [16] Subsequently, different families of heterocycles containing 2 or 4 nitrogen atoms were used as scaffolds for synthesizing reversible and selective monoamine oxidase inhibitors. [17-23] 2-Pyrazolines, which form one of these families, can also be considered as a cyclic hydrazine derivative. On the basis of the clinical 
profiles of hydrazine and other heterocycles, researchers focused on structural modifications of the pyrazoline to enhance the pharmacological activity. Various pyrazoline derivatives were synthesized and screened for their monoamine oxidase (MAO), bovine serum amine oxidase (BSAO), semicarbazide sensitive amine oxidase (SSAO) activities. A considerable number of the prepared compounds were found to have BSAO, SSAO and MAO inhibitory activities comparable to or higher than the reference compounds. [24-34]

In the light of the aforementioned findings and continuing our study of pyrazoline derivatives as potential inhibitors of MAO-A and MAO-B isoforms, we synthesized a series of 30 new pyrazoline derivatives which possess a stereogenic center on the five position of the ring and 9 new hydrazon derivatives. New compounds were screened for their in vitro hMAO inhibitory activities using recombinant hMAO isoforms. All compounds inhibited hMAO-A potently, selectively and reversibly. Five compounds of these series exhibiting highest inhibitory potency and selectivity towards hMAO-A were assessed for acute and subchronic antidepressant effects using Porsolt's forced swimming test (PFST) on mice. Our data elicited that they have an antidepressant-like action in mice by possibly interacting with the monoaminergic and serotonergic system [Umut Salgın Gökşen, Unpublished results].

Then, we decided to do semipreparative chromatographic enantioseparation of the most potent and selective compound and to see the effect of the enantiomers on the MAO activity. We established the absolute configuration using VCD. To this end the $\boldsymbol{R}$ and $\boldsymbol{S}$ enantiomers of the biologically active 1-[2-(2-benzoxazolinone-3-yl)acetyl]-3-phenyl-5-(3,4dimethoxyphenyl)-4,5-dihydro-(1H)-pyrazole resolved on a chiral stationary phase were also submitted to in vitro biological evaluation. The results revealed that the $R$-enatiomer shows higher MAO-A inhibitory activity than the S-enantiomer.

\section{MATERIALS AND METHODS}

\section{General information}

All chemicals and solvents used were purchased from Merck A.G. and Aldrich Chemical Co. The melting point of the new compound $\mathbf{5}$ was determined using a Thomas Hoover Capillary Melting Point Apparatus. The specific rotations of the enantiomers dissolved in acetone were determined using a Polarimeter Rudolph Autopol IV at $25^{\circ} \mathrm{C}$ operating at the sodium $\mathrm{D}$ line. The infrared (IR) spectra were obtained using a Perkin Elmer Spectrum One and a Nicolet 520 FTIR spectrometer. ${ }^{1} \mathrm{H}$ NMR spectra in dimethylsulfoxide (DMSO- $d_{6}$ ) were recorded on a Bruker $400 \mathrm{MHz}$ UltraShield spectrometer. Electron impact mass spectrometry of the sample in methanol was performed using a Waters 2695 Alliance Micromass ZQ LC/MS spectrometer. Elemental analysis $(\mathrm{C}, \mathrm{H}, \mathrm{N})$ was performed using a LECO CHNS 932 analyzer. The purity of the compound was assessed by TLC on silicagel $\mathrm{HF}_{254+366}$. 


\section{Synthesis and Structural Elucidation}

2-Benzoxazolinone (1), ethyl (2-benzoxazolinone-3-yl) acetate (2) and 2-(2-benzoxazolinone3-yl)acetylhydrazine (3) were synthesized according to previous methods. [35-37]

1-Phenyl-3-(3,4-dimethoxyphenyl)-2-propen-1-one (4) (chalcone). Preparation of 4 was done according to a previously described method, [38] providing the chalcone $(2.36 \mathrm{~g}, 88 \%)$. $\mathrm{mp} 86.5-88.5^{\circ} \mathrm{C}$ (from ethanol:water (3:1)) (lit., $88^{\circ} \mathrm{C}[39,40]$ ).

\section{1-[2-(2-Benzoxazolinone-3-yl)acetyl]-3-phenyl-5-(3,4-dimethoxyphenyl)-4,5-dihydro-}

(1H)-pyrazole (5). 2-(2-Benzoxazolinone-3-yl)acetylhydrazine $3(1 \mathrm{mmol})$ was dissolved in 2 $\mathrm{mL}$ of DMF and $20 \mathrm{~mL}$ of $\mathrm{n}$-propanol. Chalcone $4(1 \mathrm{mmol})$ and eight drops of hydrochloric acid were added to this solution and the latter refluxed for approximately 120 h.[41] The reaction mixture was then cooled and the precipitate was recrystallized to give the 4,5dihydro-( $1 H$ )-pyrazole $(0.18 \mathrm{~g}, 13 \%)$ as a white crystal. mp $204-204.5^{\circ} \mathrm{C}$ (from acetone:water $(3: 1))$.

The purity of the synthesized compound was checked by elemental analysis. Its structure was determined using a combination of IR, ${ }^{1} \mathrm{H} N M R,{ }^{13} \mathrm{C} N M R$ and ESI-MS. Both enantiomers exhibited identical IR, ${ }^{1} \mathrm{H}$ NMR, ${ }^{13} \mathrm{C}$ NMR and Mass spectra.

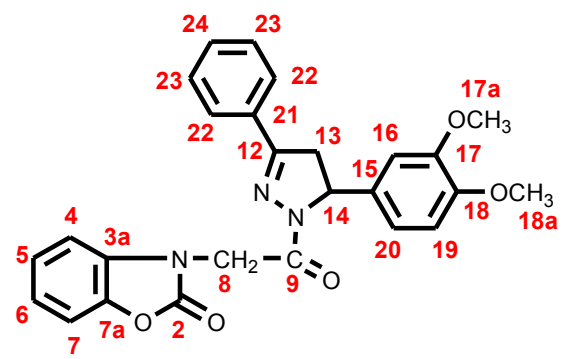

The IR, ${ }^{1} \mathrm{H}$ NMR, ${ }^{13} \mathrm{C}$ NMR and Mass spectral data are found to be: IR $\mathrm{V}_{\max } / \mathrm{cm}^{-1}: 3069,3000$, 2944, $2839(\mathrm{C}-\mathrm{H}), 1769,1680(\mathrm{C}=\mathrm{O}), 1603,1520,1490,1439(\mathrm{C}=\mathrm{C}, \mathrm{C}=\mathrm{N}), 1369,1237$, 1140, 1020 (C-O-C, C-N); ${ }^{1} \mathrm{H}$ NMR $\left(400 \mathrm{mHz}, \mathrm{DMSO}-d_{6}\right) \delta(\mathrm{ppm}) \mathrm{J}(\mathrm{Hz}) ; 3.24(1 \mathrm{H}, \mathrm{dd}, \mathrm{H}-$ 13a, $\left.\mathrm{J}_{A B}: 18.3 \mathrm{~Hz}, \mathrm{~J}_{\mathrm{AX}}: 5.0 \mathrm{~Hz}\right), 3.716(3 \mathrm{H}, \mathrm{s}, \mathrm{H}-17 \mathrm{a}), 3.722(3 \mathrm{H}, \mathrm{s}, \mathrm{H}-18 \mathrm{a}), 3.91(1 \mathrm{H}, \mathrm{dd}, \mathrm{H}-$ 13b, JAB:18.2 Hz, J $\left.\mathrm{JX}_{\mathrm{BX}}: 11.7 \mathrm{~Hz}\right), 5.10(1 \mathrm{H}, \mathrm{d}, \mathrm{H}-8 \mathrm{a}, \mathrm{J}: 17.6 \mathrm{~Hz}), 5.26(1 \mathrm{H}, \mathrm{d}, \mathrm{H}-8 \mathrm{~b}, \mathrm{~J}: 17.6 \mathrm{~Hz})$, $5.54\left(1 \mathrm{H}, \mathrm{dd}, \mathrm{H}-14, \mathrm{~J}_{\mathrm{BX}}: 11.6 \mathrm{~Hz}, \mathrm{~J}_{\mathrm{AX}}: 5.0 \mathrm{~Hz}\right), 6.75\left(1 \mathrm{H}, \mathrm{dd}, \mathrm{H}-20, \mathrm{~J}_{1}: 8.3 \mathrm{~Hz}, \mathrm{~J}_{2}: 1.9 \mathrm{~Hz}\right), 6.82$ $(1 \mathrm{H}, \mathrm{d}, \mathrm{H}-16, \mathrm{~J}: 1.9 \mathrm{~Hz}), 6.89(1 \mathrm{H}, \mathrm{d}, \mathrm{H}-19, \mathrm{~J}: 8.4 \mathrm{~Hz}), 7.13(1 \mathrm{H}, \mathrm{t}, \mathrm{H}-5), 7.19(1 \mathrm{H}, \mathrm{t}, \mathrm{H}-6), 7.28$ $\left(1 \mathrm{H}, \mathrm{d}, \mathrm{H}-4, \mathrm{~J}_{45}: 7.6 \mathrm{~Hz}\right), 7.36\left(1 \mathrm{H}, \mathrm{d}, \mathrm{H}-7, \mathrm{~J}_{67}: 7.7 \mathrm{~Hz}\right), 7.49-7.52(3 \mathrm{H}, \mathrm{m}, \mathrm{H}-23$ and $\mathrm{H}-24)$, 7.86-7.88 (2H, m, H-22); ${ }^{13} \mathrm{C}$ NMR (400 mHz, DMSO-d 6 ) $\delta$ (ppm); 42.0 (C-13), 43.8 (C-8), 55.4 (C-17a), 55.5 (C-18a), 59.9 (C-14), 109.4 (C-7), 109.5 (C-5 ve C-6), 111.9 (C-4), 117.3 (C-16), 122.2 (C-19), 123.8 (C-20), 126.9 (C-23), 128.7 (C-22), 130.61 (C-24), 130.65 (C3a), 131.4 (C-21), 133.9 (C-15), 141.8 (C-7a), 148.0 (C-18), 148.8 (C-17), 154.0 (C-12), 156.0 (C-2), 163.1 (C-9); ESI-MS m/z: $496\left([\mathrm{M}+\mathrm{K}]^{+}, 3 \%\right), 481\left([\mathrm{M}+\mathrm{H}+\mathrm{Na}]^{+}, \% 31\right), 480$ 
$\left.\left([\mathrm{M}+\mathrm{Na}]^{+}, \% 100\right), 458\left([\mathrm{M}+\mathrm{H}]^{+}\right), \% 17,\right) 320\left(\left[\mathrm{M}^{+}-\mathrm{C}_{6} \mathrm{H}_{3}\left(\mathrm{OCH}_{3}\right)_{2}\right]^{+}, \% 17\right), 176$ ([2-benzoks.- $\mathrm{CH}_{2^{-}}$ $\mathrm{CO}^{+}, \% 13$ ), 148 (2-benzoks.- $\left.\mathrm{CH}_{2}\right]^{+}, \% 16$ ). Found: C, 68.18; H, 5.06; N, 9.15. Calculated for $\mathrm{C}_{26} \mathrm{H}_{23} \mathrm{~N}_{3} \mathrm{O}_{5}$ : C, 68.26; $\mathrm{H}, 5.07 ; \mathrm{N}, 9.19$.

\section{Analytic Separation \& Stereochemistry - HPLC analysis}

Liquid chromatography was performed using an ultraviolet (UV) detector Shimadzu SPD-6A $(\lambda=254 \mathrm{~nm})$ in combination with a CHIRALPAK AD-H column packed with amylose tris $(3,5-$ dimethylphenylcarbamate) (the column for the analyses had particle size $5 \mu \mathrm{m}$; column size $250 \times 4.6 \mathrm{~mm}$, the semi-preparative column had particle size $5 \mu \mathrm{m}$; column size $250 \times 10 \mathrm{~mm}$ ) as stationary phase at $35^{\circ} \mathrm{C}$. The chromatograms were recorded and the chromatographic peaks were integrated using the Shimadzu C-R6A Chromatopac software.

\section{Vibrational Circular Dichroism (VCD) spectra}

The stereochemistry of the separate enantiomers was determined by Vibrational Circular Dichroism (VCD). IR and VCD spectra of the compounds were obtained using a BioTools ChirallR-2X dual PEM spectrometer. Solutions containing up to $3.0 \mathrm{mg}$ of the samples from both fractions from the analytical separation were dissolved in $\mathrm{CDCl}_{3}$. Spectra were recorded in a 100 micron liquid cell equipped with $\mathrm{BaF}_{2}$ windows. For both enantiomers, 40000 scans were recorded at $4 \mathrm{~cm}^{-1}$ resolution and averaged. The analysis reported below is based on the experimental spectra of the first eluent. A virtual racemate was used for baseline subtraction. Hence, spectra for the two enantiomers are exact mirror images.

Extensive conformational analyses were performed using the MMFF94S [42] MMF [43] and SYBYL[44] force fields using the Monte Carlo and reservoir-filling algorithms, as implemented in the Spartan08 [45] and Conflex [46,47] software packages respectively. The geometries derived from the molecular mechanics simulations were optimized at the Density Functional Theory level using Gaussian 09 [48] using the B3LYP/6-31G* and B3LYP/ccpVTZ combinations of DFT functional and basis set and a SCRF model to account for solvent interactions. Boltzmann weighted IR and VCD spectra were obtained by assuming Lorentzian band profiles with a FWHH of $10 \mathrm{~cm}^{-1}$. The Boltzmann populations used were based on the standard enthalpies obtained. Inspection of the data shows that enlarging the basis set from $6-31 G^{*}$ to cc-pVTZ only has a minor influence on the IR and VCD spectra. Both the experimental and theoretical spectra are shown in figure 1. 

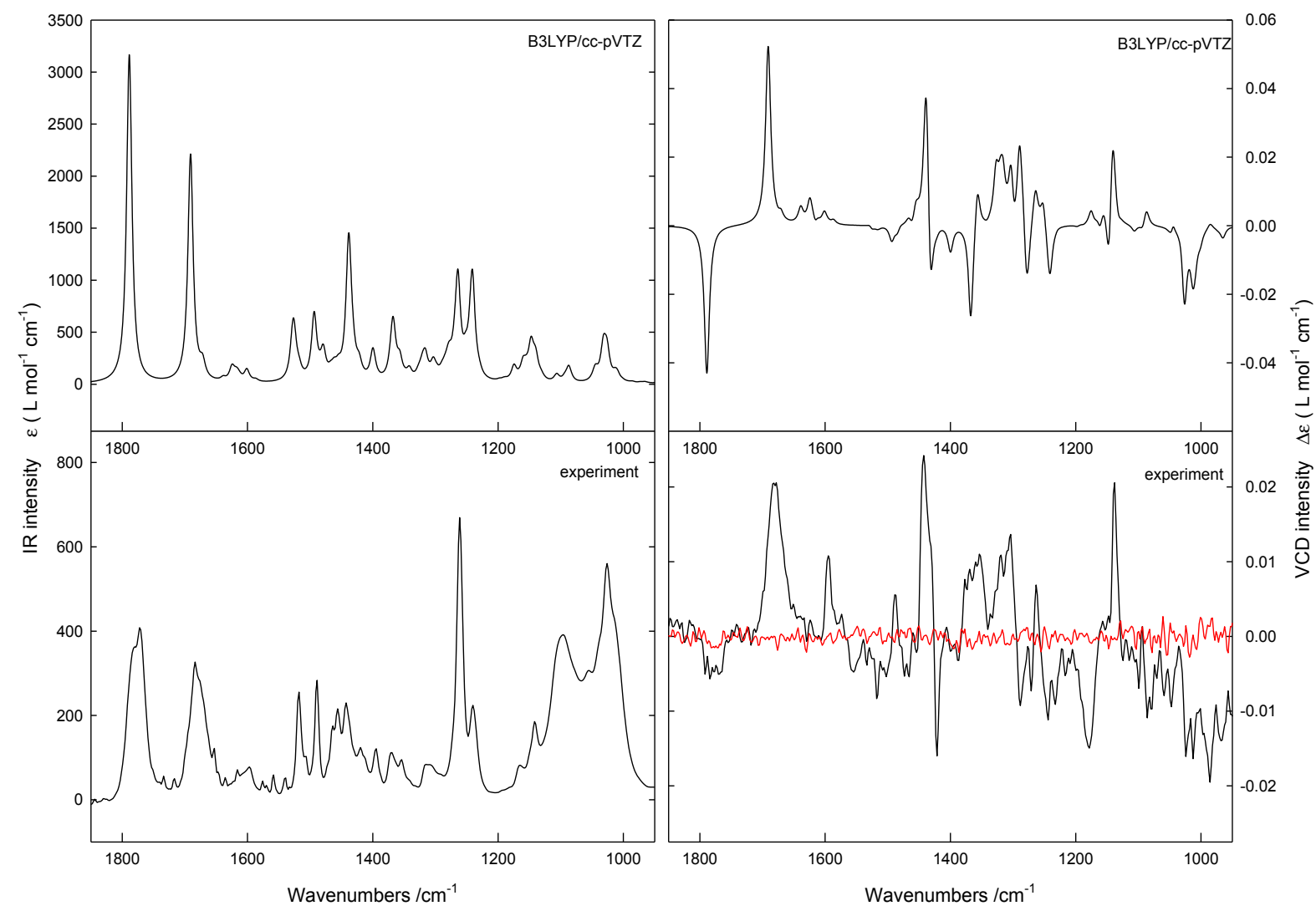

Figure 1. Experimental and calculated IR and VCD spectra obtained for the $\boldsymbol{R}$ enantiomer of 1-[2-(2-benzoxazolinone-3-yl)acetyl]-3-phenyl-5-(3,4-dimethoxyphenyl)-4,5-dihydro- $1 \mathrm{H}$ pyrazole. For the experimental VCD spectra, the noise was added as a solid line in red. Due to the use of a virtual racemate for baseline subtractions, the experimental spectra for the $R$ and $\mathrm{S}$ enantiomers are perfect mirror images.

\section{Biochemistry}

\section{Material}

Recombinant hMAOs and other chemicals were purchased from Sigma-Aldrich. The Amplex®-Red MAO assay kit was obtained from Molecular Probes (Invitrogen Detection Technologies), USA.

\section{Determination of MAO Activity}

The Amplex® Red MAO Assay Kit provides a one-step fluorometric method for the continuous measurement of MAO activity using a fluorescence microplate reader. $[49,50]$ The assay is based on the detection of $\mathrm{H}_{2} \mathrm{O}_{2}$ in a horse radish peroxidase coupled reaction using the Amplex Red reagent, a highly sensitive and stable probe for $\mathrm{H}_{2} \mathrm{O}_{2}$. Since resorufin, the reaction product, has absorption and fluorescence emission maxima of $571 \mathrm{~nm}$ and 585 $\mathrm{nm}$, respectively, there is no significant interference from auto fluorescence. 
Recombinant enzymes were diluted in a reaction buffer (containing $0.25 \mathrm{M}$ of sodium phosphate, $\mathrm{pH}$ 7.4). $100 \mu \mathrm{L}$ hMAO-A or MAO-B solution was incubated with $0.2 \mu \mathrm{L}$ of inhibitor stock solution (clorgyline or pargyline, $0.5 \mathrm{mM}$ ) at room temperature for $30 \mathrm{~min}$. Enzyme and inhibitor concentrations were kept as twofold lower in the final reaction volume. The positive control solution was prepared by diluting the $20 \mathrm{mM} \mathrm{H}_{2} \mathrm{O}_{2}$ working solution to the final concentration of $10 \mu \mathrm{M}$ in the reaction buffer whereas the reaction buffer without $\mathrm{H}_{2} \mathrm{O}_{2}$ was prepared as the negative control. The reaction was started by adding $100 \mu \mathrm{L}$ of the Amplex Red reagent to each microplate well containing the samples and controls. The mixtures were incubated for 30 minutes at room temperature. The fluorescence was measured using excitation at $530 \mathrm{~nm}$ and emission at $590 \mathrm{~nm}$ at multiple time points to follow the kinetics of the reactions. Background fluorescence was corrected by subtracting the values derived from the control (no enzyme). The possible capacity of the new compounds to modify the fluorescence generated in the reaction mixture due to non-enzymatic inhibition was determined by adding these compounds to solutions containing only the Amplex Red reagent in a sodium phosphate buffer. The newly synthesized compounds were tested for their possible interactions with Amplex Red reagent according to the method previously decribed [49-51) and it was found that our compounds did not directly react with Amplex Red reagent.

\section{Kinetic Studies}

The synthesized derivatives were dissolved in dimethyl sulfoxide (DMSO), with a maximum concentration of $1 \%$ and used in a wide concentration range of $0.10-200.00 \mu \mathrm{M}$. The reference inhibitors were also dissolved in DMSO in a concentration range of 0.001-20.00 $\mu \mathrm{M}$. The mode of MAO inhibition was examined using Lineweaver-Burk plotting. The slopes of the Lineweaver-Burk plots were plotted versus the inhibitor concentration and the $K_{i}$ values were determined from the $\mathrm{x}$-axis intercept as $-\mathrm{K}_{\mathrm{i}}$. Each $\mathrm{K}_{\mathrm{i}}$ value is the representative of single determination where the correlation coefficient $\left(R^{2}\right)$ of the replot of the slopes versus the inhibitor concentrations was at least 0.98. The selectivity index (SI) was calculated as $\mathrm{K}_{\mathrm{i}}(\mathrm{hMAO}-\mathrm{A}) / \mathrm{K}_{\mathrm{i}}(\mathrm{hMAO}-\mathrm{B})$. The protein concentration was determined according to the Bradford method. [52]

\section{Reversibility Studies}

The reversibility of the hMAO inhibition with the new compounds was determined by dialysis as previously described [53]. Dialysis tubing $16 \times 25 \mathrm{~mm}$ (SIGMA) with a molecular weight cutoff of $12000 \mathrm{Da}$ and a sample capacity of $0.5-10 \mathrm{~mL}$ was used. Adequate amounts of the recombinant enzymes ( $\mathrm{hMAO}-\mathrm{A}$ or $\mathrm{B})(1 \mathrm{U} / \mathrm{mL}$ ) and the inhibitors at a concentration equal to fourfold the $\mathrm{IC}_{50}$ values for the inhibition of hMAO-A and $-\mathrm{B}$, were incubated in a potassium phosphate buffer $(0.05 \mathrm{M}, \mathrm{pH} 7.4,5 \%$ sucrose containing $1 \% \mathrm{DMSO})$ for $15 \mathrm{~min}$. at $37^{\circ} \mathrm{C}$. Another set was prepared by preincubation of the same amount of hMAO-A and -B with the 
reference inhibitors. The enzyme-inhibitor mixtures were subsequently dialyzed at $4{ }^{\circ} \mathrm{C}$ in 80 $\mathrm{mL}$ of the dialysis buffer (100 mM potassium phosphate, $\mathrm{pH} 7.4,5 \%$ sucrose). The dialysis buffer was replaced with fresh buffer twice during the 24 hours of dialysis. After dialysis, residual MAO activities were measured and expressed as mean \pm SEM. For comparison, undialyzed mixtures of the MAOs and the inhibitors were included in the study.

\section{Cytotoxicity Studies}

The cell viability was determined by a MTT assay [54]. Human hepatoma cell line HepG2 (Invitrogen) was used. The cells were exposed to $\mathbf{5 R}$ and $\mathbf{5 S}$ at the concentrations of 1,5 and $25 \mu \mathrm{M}$, and $0.1 \%$ DMSO as a vehicle control for 24 hours. Control cells treated with $0.1 \%$ DMSO were used as $100 \%$ viability. [55] Results were expressed as mean \pm SEM. Differences are considered statistically significant at $p<0.05$.

\section{Molecular Modeling Studies}

The crystal structures of MAO-A and MAO-B were extracted from the PDB (http://www.rcsb.org, for MAO-A pdb code: 2Z5X; human monoamine oxidase in complex with harmine, resolution $2.2 \AA$ [56] and for MAO-B pdb code: $2 \mathrm{~V} 5 \mathrm{Z}$; human MAO-B in complex with inhibitor safinamide, resolution $1.6 \AA$ [57]). Each structure was cleaned of all water molecules and inhibitors as well as all non-interacting ions before being used in the docking studies. The initial oxidized form of the FAD was used in all docking studies. For MAO-A and MAO-B, one of the two subunits was taken as the target structure. Using a fast Dreiding-like force field [58] each protein's geometry was first optimized and then submitted to the "Clean Geometry" toolkit of the Discovery Studio (Accelrys, Inc.) for a more complete check. Missing hydrogen atoms were added based on the protonation state of the titratable residues at a $\mathrm{pH}$ of 7.4. The ionic strength was set to 0.145 and the dielectric constant was set to 10. The AutoDock Tools (vv. 1.5.4) (ADT) [59] graphical user interface program was employed to setup the enzymes for molecular docking.

The 3D structures of the ligand molecules were built, optimized at PM3 level and saved in $\mathrm{pdb}$ format. The ADT package was also employed to generate the docking input files of the ligands. AutoDock 4.2.6 was used for all dockings; the detailed docking procedure has been given elsewhere [60] and the detailed procedure was reported in our earlier work [61].

\section{RESULTS AND DISCUSSION}

\section{Synthesis and characterization}

The synthesis pathway of 1-[2-(2-benzoxazolinone-3-yl)acetyl]-3-phenyl-5-(3,4dimethoxyphenyl)-4,5-dihydro-1 $\mathrm{H}$-pyrazole is given in Scheme 1 . Treatment of 2benzoxazolinone 1 with ethyl chloroacetate in $\mathrm{K}_{2} \mathrm{CO}_{3}$ /acetone gave the $\mathrm{N}$-alkylated product ethyl (2-benzoxazolinone-3-yl) acetate 2. [35] The acid hydrazide 3 was prepared by the 
reaction of ethyl (2-benzoxazolinone-3-yl) acetate and hydrazine hydrate in ethanol. [36,37] On the other hand, $\alpha, \beta$-unsaturated carbonyl compound (chalcone) $\mathbf{4}$ was prepared by reacting 3,4-dimethoxybenzaldehyde and acetophenone under basic condition according to the Claisen-Schmidt condensation. [38] The reaction of hydrazide 3 with chalcone 4 in npropanol under acidic condition gave compound 1-[2-(2-benzoxazolinone-3-yl)acetyl]-3phenyl-5-(3,4-dimethoxyphenyl)-4,5-dihydro-1H-pyrazole 5 (Scheme 1).

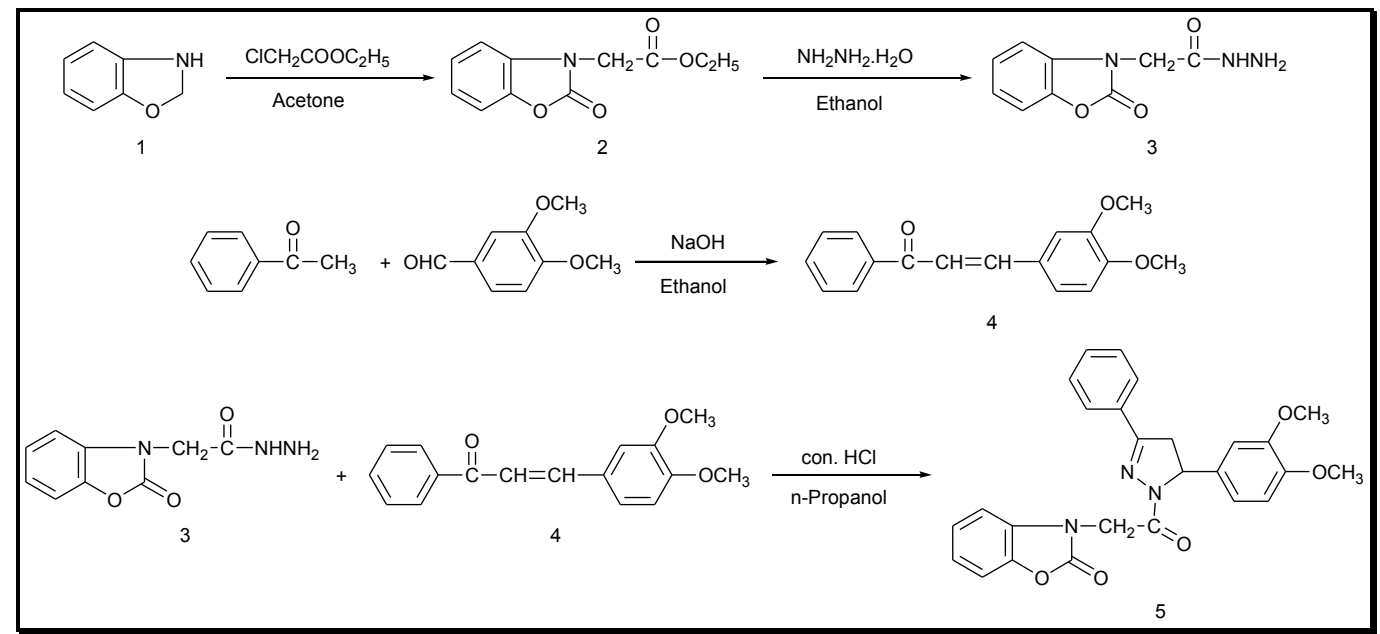

Scheme 1. Synthesis pathway of 1-[2-(2-benzoxazolinone-3-yl)acetyl]-3-phenyl-5-(3,4dimethoxyphenyl)-4,5-dihydro-1 $H$-pyrazole 5.

Both enantiomers exhibited identical IR, ${ }^{1} \mathrm{H}$ NMR, ${ }^{13} \mathrm{C}$ NMR and Mass spectra. The IR spectrum of 5 revealed two stretching bands at $1769 \mathrm{~cm}^{-1}$ and $1680 \mathrm{~cm}^{-1}$ due to the carbonyl function of the lactam and acetyl groups, respectively. $\mathrm{C}=\mathrm{C}, \mathrm{C}=\mathrm{N}$ and $\mathrm{C}-\mathrm{O}-\mathrm{C}, \mathrm{C}-\mathrm{N}$ stretching bands were found near $1603-1439 \mathrm{~cm}^{-1}$ and $1369-1020 \mathrm{~cm}^{-1}$, respectively. The existence of the $\mathrm{C}=\mathrm{N}$ stretching bands and disappearance of the $\mathrm{N}-\mathrm{H}$ stretching bands proves the closure of the 4,5-dihydro-(1H)-pyrazole ring. Aromatic and aliphatic $\mathrm{C}-\mathrm{H}$ stretching bands were observed near $3069-2839 \mathrm{~cm}^{-1}$.

In the ${ }^{1} \mathrm{H}$ NMR spectrum of $\mathbf{5}$, multiplet or doublet peaks belonging to the protons of aromatic rings were observed at 7.88-6.75 ppm. Three distinct doublet of doublets of the ABX system in the 4,5-dihydro-(1H)-pyrazole ring (a $\mathrm{CH}$ proton and two anisochronous protons of a $\mathrm{CH}_{2}$ ) appeared at 5.54-3.24 ppm. The $\mathrm{CH}\left(\mathrm{H}_{\mathrm{x}}\right)$ proton appeared at $5.54 \mathrm{ppm}$ due to vicinal coupling with the two magnetically non-equivalent protons of the methylene group at position 4 of the 4,5-dihydro- $(1 H)$-pyrazole ring. The signals of $\mathrm{H}_{\mathrm{A}}$ and $\mathrm{H}_{\mathrm{B}}$ of the 4,5-dihydro- $(1 H)$ pyrazole ring were observed as doublet of doublets at 3.24 and $3.91 \mathrm{ppm}$, respectively. The $\mathrm{CH}_{2}$ protons between the 2-benzoxazolinone and 4,5-dihydro-(1H)-pyrazole ring resonated as a pair of doublet of doublets at 5.10 and $5.26 \mathrm{ppm}$. The signals for methoxy groups appeared at $3.72 \mathrm{ppm}$ as two separate peaks. Additional support for the structure of $\mathbf{5}$ was provided by ${ }^{13} \mathrm{C}$ NMR spectra. In the ${ }^{13} \mathrm{C} N M R$ spectra the lactam and acetyl $\mathrm{C}=\mathrm{O}$ groups 
gave two peaks at around 156 and $163 \mathrm{ppm}$. The peak at $154 \mathrm{ppm}$ in the ${ }^{13} \mathrm{C}$ NMR spectrum, assigned to the $\mathrm{C}=\mathrm{N}$ moiety confirms the closure of 4,5-dihydro- $(1 H)$-pyrazole ring). The ions produced under electrospray ionization showed a characteristic $[\mathrm{M}+\mathrm{Na}]^{+}$ion peak as the base signal in the mass spectrum.

\section{Analytic Separation \& Absolute configuration}

Since it is known that the two enantiomers of a chiral molecule may exhibit different biological activities [62-65] we have decided to separate both enantiomers to evaluate their separate selective human MAO inhibitory activities. This separation was achieved for both enantiomers of 5 using analytic and semipreparative HPLC.

During the separation, the compound was dissolved in methanol and $30 \mu \mathrm{L}$ was injected to the column. The choice of the eluent was done as follows: First, different ratios of hexane:ethanol mixtures were tried as the mobile phase, however, none of them could resolve the compound into its enantiomers. Therefore, it was decided to use a more polar mobile phase. When an ethanol:methanol mixture with 80:20 ratio was used, the resolution was again not achieved. The enantiomers were finally resolved analytically with the separation factor $(\alpha)$ of 1.36 when a 50:50 ethanol:methanol mixture was used as the eluent (flow rate $0.4 \mathrm{~mL} / \mathrm{min}$ ). The enantiomers were then collected by semi-preparative HPLC using an CHIRALPAK AD-H semi-preparative column under the same conditions. $100 \mu \mathrm{L}$ multiple injections of the racemate afforded pure enantiomers (Figure 2).

1. eluent (R-enantiomer): $\left.[\alpha]^{25}{ }_{365}=+(25 \pm 3)\right)($ c $0.0008 \mathrm{~g} / \mathrm{mL}$ in acetone).

2. eluent (S-enantiomer): $[\alpha]^{25}{ }_{365}=-(25 \pm 3)$ (c $0.0009 \mathrm{~g} / \mathrm{mL}$ in acetone).

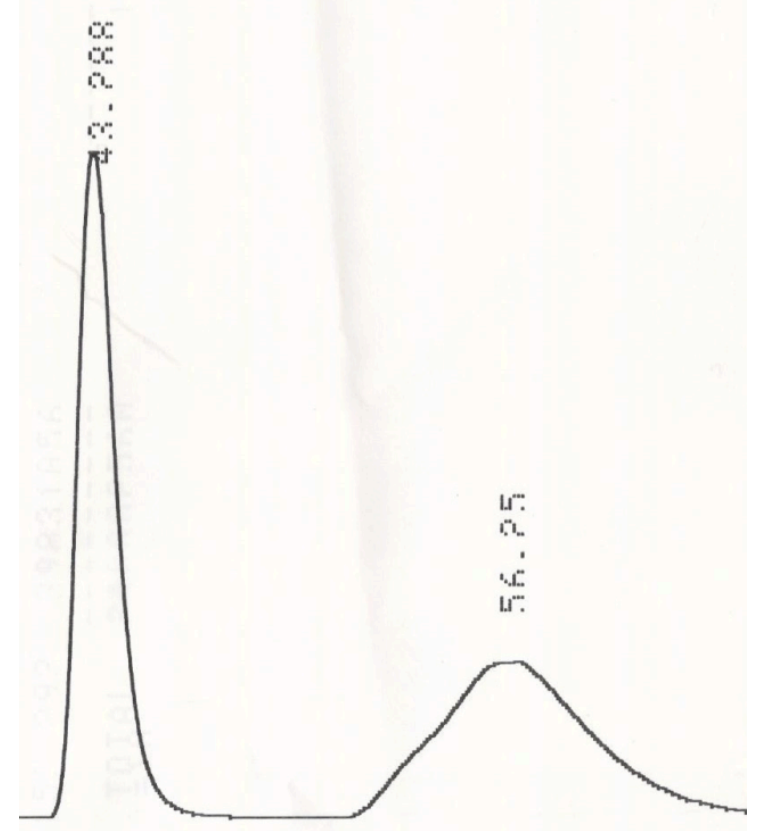


Figure 2. HPLC chromatogram of 5 showing the $1^{\text {st }}$ eluted, (retention time $43.29 \mathrm{~min}$ ) and the $2^{\text {nd }}$ eluted, (retention time $56.25 \mathrm{~min}$ ) enantiomer at $35{ }^{\circ} \mathrm{C}$. Column: Chiralpak AD-H, Eluent (v/v) 50:50 ethanol:methanol flow rate: $0.4 \mathrm{~mL} / \mathrm{min}(\alpha): 1.36$.

The measurement of circular dichroism associated with molecular vibrational transitions is referred to as vibrational circular dichroism (VCD) [66-68]. The assignment of the absolute configuration of the collected enantiomers was performed using VCD. The experimental IR and VCD spectra for the first eluent and the calculated IR and VCD spectra for the $R$ enantiomer obtained at the B3LYP/cc-pvTZ level are shown in the Figure 1. Due to the limited amount of sample available, the absorbances in IR are rather small and the corresponding VCD spectrum is characterized by a substantial noise level. However, in general good agreement is found in which most, if not all, of the characteristic features observed are reproduced by the calculations. The agreement between experiment and theory, allows the characterization of the absolute configuration of the first eluent as $\boldsymbol{R}$ and that of the second eluent as $S$.

Numerical data confirming the assignment of the absolute configuration of the first eluent as the $\boldsymbol{R}$ enantiomer and the second eluent as the $\boldsymbol{S}$ enantiomer was obtained using the CompareVOA algorithm described in ref [69]. The B3LYP/cc-pVTZ IR similarity index, using a scaling factor for the calculated frequencies of 0.985 , and based upon the $1000-1800 \mathrm{~cm}^{-1}$ spectral range studied, is determined to be $65.1 \%$. As IR spectra are the same for enantiomers, they also share the same value for the similarity index. Using the experimental spectrum of the first eluent, we computed the similarity index between this experimental spectrum and the theoretical spectra of the the $\boldsymbol{R}$ and $\boldsymbol{S}$ enantiomers. The results are 68.5 and $19.6 \%$, respectively, which leads to an enantiomeric similarity index of $48.9 \%$. This establishes that the first eluent corresponds to the R enantiomer. The confidence level for the assignment, based on the localization of the current assignments with respect to the database of correct and incorrect assignments contained in the CompareVOA algorithm, is $99 \%$. All calculations and analysis were repeated at the B3LYP/ 6-31G* level of theory and resulted in very similar results albeit slightly worse. Likewise, for the second eluent the CompareVOA algorithm revealed that it corresponds to the $\mathbf{S}$ enantiomer.

The similarity index for IR is substantially lower than the values obtained in many other studies. This deviation, most probably, is related to the appearance of a broad intense spectral feature in the experimental spectrum near $1000 \mathrm{~cm}^{-1}$ while no such band is observed in the calculated spectra. The origin of this band could not be established but all spectroscopic data together clearly establish the (absolute) chemical structure of the compound.

\section{Biochemistry}


The newly synthesized compound $\mathbf{5}$ (in racemic form) was screened for its inhibitory activity towards human recombinant MAO-A and -B. Specific enzyme activities were calculated as $0.171 \pm 0.008 \mathrm{nmol} /(\mathrm{mg} \cdot \mathrm{min})(\mathrm{n}=3)$ for $\mathrm{hMAO}-\mathrm{A}$ and $0.133 \pm 0.009 \mathrm{nmol} /(\mathrm{mg} \cdot \mathrm{min})(\mathrm{n}=3)$ for hMAO-B. The selectivity index (SI) was expressed as $K_{i}(M A O-A) / K_{i}(M A O-B) .5$ was found to inhibit hMAO-A selectively and competitively since the $\mathrm{IC}_{50}$ value for hMAO-A inhibition was calculated as $1.20 \pm 0.02 \mu \mathrm{M}$ whereas the $\mathrm{IC}_{50}$ value for hMAO-B inhibition was calculated as 425.88 $\pm 16.45 \mu \mathrm{M}$. Its experimental $\mathrm{SI}\left(\mathrm{K}_{i}(\mathrm{MAO}-\mathrm{A}) / \mathrm{K}_{\mathrm{i}}(\mathrm{MAO}-\mathrm{B})\right)$ was found to be 0.003 .

For the kinetic experiments, the catalytic rates of hMAO-A and -B at different $p$-tyramine concentrations were measured. Lineweaver-Burk graphs were constructed in the absence of the inhibitor, and in the presence of compound $\mathbf{5}$ or $\mathbf{5 R}$ or $\mathbf{5 S}$ and reference inhibitors. Since the lines are linear and intersect on the $y$-axis, compounds $5,5 R$ and $\mathbf{5} S$ are suggested to be competitive inhibitors of hMAO-A which may interact within the catalytic site of hMAO-A. $K_{i}$ values for hMAO-A and -B inhibition for 5 (racemic form) were determined as $0.91 \times 10^{-}$ ${ }^{3} \pm 0.01 \times 10^{-3} \mu \mathrm{M}$ and $20.00 \pm 1.55 \mu \mathrm{M}$, respectively (Table 1 ). The experimental SI for 5 was found as $4.55 \times 10^{-5}$ showing that it is a remarkably selective and potent MAO-A inhibitor.

Turning to the individual isomers, isolated enantiomer $5 \boldsymbol{R}$ inhibited both hMAO-A and -B potently. However, this compound was found to inhibit hMAO-A more potently $\left(\mathrm{K}_{\mathrm{i}}=0.85 \times 10^{-}\right.$ ${ }^{3} \pm 0.05 \times 10^{-3} \mu \mathrm{M}$ for hMAO-A). The experimental SI value of $5 \boldsymbol{R}$ was found as $2.35 \times 10^{-5}$ showing that this derivative is highly selective towards hMAO-A when compared with the kinetic data of moclobemide, a known selective MAO-A inhibitor (Table 1). The kinetic behavior of $5 \boldsymbol{R}$ is indicated in Figure 3. $5 \boldsymbol{S}$ also inhibited hMAO-A and -B potently. However, the $\mathbf{S I}$ of $\mathbf{5 S}$ was calculated as 0.001 which is poorer than that of compound $\mathbf{5 R}$. The reversibility tests were carried out using the dialysis method. [70] Compound 5, and its enantiomers $\mathbf{5 R}$ and $\mathbf{5 S}$ appeared as reversible inhibitors of hMAO-A (Table 2). As seen in table II, moclobemide, a known selective MAO-A inhibitor, strongly inhibited hMAO-A. Following incubation of the enzyme with moclobemide, the remaining MAO-A activity was determined as $34.3 \pm 1.4 \%$. hMAO-A activity was recovered up to $91.2 \pm 2.9 \%$ after dialysis indicating that the inhibition is reversible. $5 \boldsymbol{R}$ inhibited hMAO-A more potently than moclobemide $(10.5 \pm 0.6 \%)$. MAO-A activity was recovered to $95.2 \pm 1.3 \%$ after dialysis indicating that the inhibition of hMAO-A with $5 \boldsymbol{R}$ is almost totally reversible.

Table 1. Calculated and experimental $K_{i}$ values corresponding to the inhibition of hMAO isoforms by 1-[2-(2-benzoxazolinone-3-yl)acetyl]-3-phenyl-5-(3,4-dimethoxyphenyl)-4,5dihydro-1H-pyrazole 5 .

\begin{tabular}{|c|c|c|c|c|c|c|c|}
\hline Compound & $\begin{array}{l}\text { Calc. } K_{i} \\
\text { value for } \\
\text { MAO-A } \\
(\mu M)\end{array}$ & $\begin{array}{l}\text { Calc. } K_{i} \\
\text { value for } \\
\text { MAO-B } \\
(\mu \mathrm{M})\end{array}$ & Calc. SI ${ }^{*}$ & $\begin{array}{l}\text { Exp } K_{i} \text { value } \\
\text { for MAO-A } \\
(\mu M)^{* *}\end{array}$ & $\begin{array}{l}\text { Exp } K_{i} \text { value } \\
\text { for MAO-B } \\
(\mu M)^{\star *}\end{array}$ & Exp. SI ${ }^{*}$ & $\begin{array}{l}\text { Inhibition } \\
\text { type, } \\
\text { selectivity, } \\
\text { reversibility }\end{array}$ \\
\hline
\end{tabular}




\begin{tabular}{|c|c|c|c|c|c|c|c|}
\hline 5 (racemic) & - & - & - & $\begin{array}{l}0.91 \times 10^{-} \\
{ }^{3} \pm 10^{-4}\end{array}$ & $20.00 \pm 1.55$ & $4.55 \times 10^{-5}$ & $\begin{array}{l}\text { MAO-A, } \\
\text { competitive, } \\
\text { reversible }\end{array}$ \\
\hline $5 R$ & $0.74 \times 10^{-}$ & 29.47 & $2.51 \times 10^{-}$ & $\begin{array}{l}0.85 \times 10^{-} \\
{ }^{3} \pm 0.05 \times 10^{-3} \\
\end{array}$ & $36.20 \pm 1.86$ & $2.35 \times 10^{-5}$ & \multirow{2}{*}{$\begin{array}{l}\text { MAO-A, } \\
\text { competitive, } \\
\text { reversible }\end{array}$} \\
\hline $5 S$ & 0.229 & 193.25 & 0.001 & $0.184 \pm 0.007$ & $175.00 \pm 9.30$ & 0.001 & \\
\hline $\begin{array}{l}\text { Selegiline } \\
\text { (MAO-B } \\
\text { inhibitor) }\end{array}$ & 22.02 & 34.07 & 0.646 & $9.060 \pm 0.44$ & $0.09 \pm 0.004$ & 100.67 & $\begin{array}{l}\text { MAO-B, } \\
\text { suicide } \\
\text { inhibitor } \\
\text { irreversible }\end{array}$ \\
\hline $\begin{array}{l}\text { Moclobemide } \\
\text { (MAO-A } \\
\text { inhibitor) }\end{array}$ & 5.71 & 250.74 & 0.023 & $0.005 \pm 0.001$ & $1.22 \pm 0.08$ & 0.004 & $\begin{array}{l}\text { MAO-A, } \\
\text { competitive, } \\
\text { reversible }\end{array}$ \\
\hline
\end{tabular}

* Selectivity index calculated as $\mathrm{K}_{\mathrm{i}}(\mathrm{MAO}-\mathrm{A}) / \mathrm{Ki}(\mathrm{MAO}-\mathrm{B})$. The Selectivity towards MAO-A increases as the corresponding SI decreases while selectivity towards MAO-B isoform increases as the corresponding $\mathrm{SI}$ increases.

${ }^{* *}$ Each value represents the mean \pm standard error of mean (SEM) of three independent experiments.

(a)

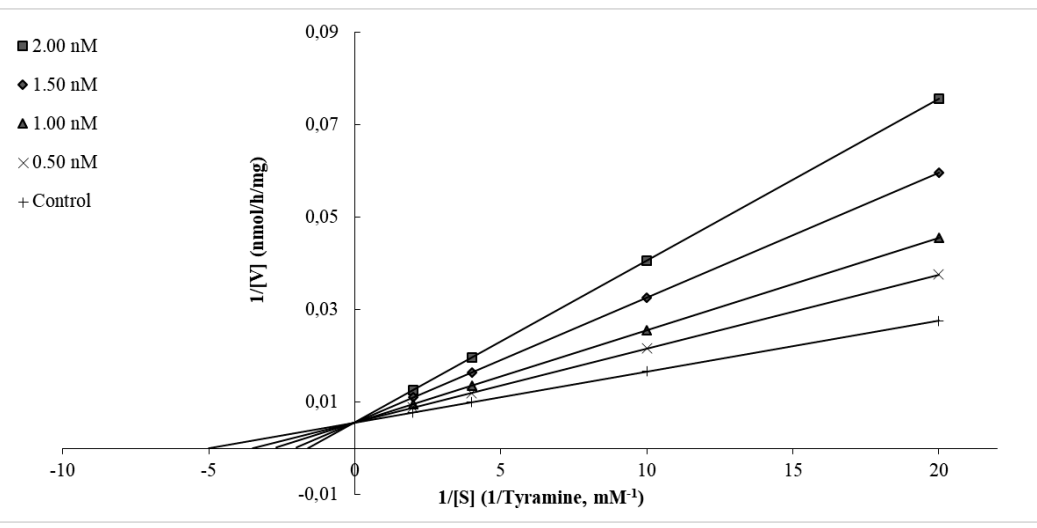

(b)

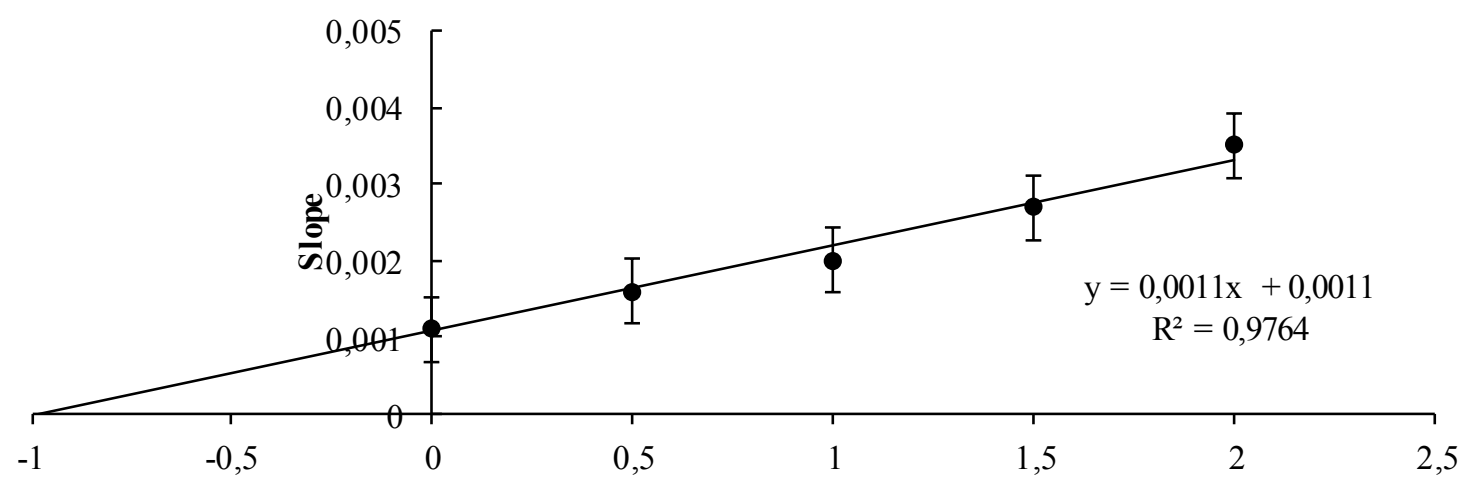

[I], $\mathbf{n M}$

Figure 3. (a) Lineweaver-Burk plots for the inhibition of hMAO-A by $\mathbf{5 R}$. [S]: substrate concentration (mM), [V]: reaction velocity (nmol/hour/mg). Inhibitor concentrations are shown at the left. (b) The second graph represents the plots of the slopes of the Lineweaver-Burk plots versus inhibitor concentration $[\mathrm{l}]$. $\mathrm{K}_{\mathrm{i}}$ was calculated as $0.85 \times 10^{-3} \pm 0.05 \times 10^{-3} \mathrm{nM}$. 
Table 2. Reversibility of the inhibition of hMAOs by the novel compounds.

\begin{tabular}{|c|c|c|c|c|c|}
\hline $\begin{array}{c}\text { Test } \\
\text { compound } \\
\text { incubated with } \\
\text { hMAO }\end{array}$ & $\begin{array}{c}\text { hMAO-A } \\
\text { activity before } \\
\text { dialysis } \\
(\%)\end{array}$ & $\begin{array}{c}\text { hMAO-A } \\
\text { activity after } \\
\text { dialysis } \\
\mathbf{( \% )}\end{array}$ & $\begin{array}{c}\text { hMAO-B } \\
\text { activity before } \\
\text { dialysis } \\
(\%)\end{array}$ & $\begin{array}{c}\text { hMAO-B } \\
\text { activity after } \\
\text { dialysis } \\
\text { (\%) }\end{array}$ & Reversibility \\
\hline $\begin{array}{c}\text { With no } \\
\text { inhibitor }\end{array}$ & $\mathbf{1 0 0 \pm 0 . 0 0}$ & $\mathbf{1 0 0 \pm 0 . 0 0}$ & $\mathbf{1 0 0 \pm 0 . 0 0}$ & $\mathbf{1 0 0 \pm 0 . 0 0}$ & \\
\hline Moclobemide & $\mathbf{3 4 . 2 8 \pm 1 . 3 7}$ & $\mathbf{9 1 . 2 2 \pm 2 . 8 8}$ & $\mathbf{7 5 . 2 9 \pm 3 . 0 1}$ & $\mathbf{9 2 . 0 0 \pm 4 . 0 0}$ & Reversible \\
\hline Selegiline & $\mathbf{9 1 . 3 1 \pm 2 . 8 4}$ & $\mathbf{9 2 . 1 6 \pm 3 . 1 4}$ & $\mathbf{5 0 . 2 9 \pm 1 . 6 6}$ & $\mathbf{5 1 . 0 2 \pm 2 . 3 0}$ & Irreversible \\
\hline $\mathbf{5}$ & $39.22 \pm 1.13$ & $92.45 \pm 2.34$ & $87.26 \pm 2.60$ & $94.11 \pm 3.27$ & Reversible \\
\hline $\mathbf{5 R}$ & $10.46 \pm 0.54$ & $95.21 \pm 1.33$ & $79.50 \pm 2.46$ & $94.00 \pm 2.14$ & Reversible \\
\hline $\mathbf{5 S}$ & $30.55 \pm 1.68$ & $93.00 \pm 2.11$ & $80.60 \pm 2.16$ & $91.33 \pm 2.00$ & Reversible \\
\hline
\end{tabular}

In vitro cytotoxicity of the new inhibitors was tested at three different concentrations (1, 5 and $25 \mu \mathrm{M}$ ) (Table 3). The results showed that they are not toxic to hepatic cells at the test concentrations.

Table 3. In vitro cytotoxicity of 1-[2-(2-benzoxazolinone-3-yl)acetyl]-3-phenyl-5-(3,4dimethoxyphenyl)-4,5-dihydro-1H-pyrazole derivatives.

\begin{tabular}{|c|c|c|c|}
\hline \multirow{2}{*}{ Compound } & \multicolumn{3}{|c|}{ Viability (\%) } \\
\cline { 2 - 4 } & $\mathbf{1} \boldsymbol{\mu M}$ & $\mathbf{5} \boldsymbol{\mu M}$ & $\mathbf{2 5} \boldsymbol{\mu M}$ \\
\hline $\mathbf{5}$ & $95.26 \pm 1.52$ & $92.25 \pm 2.01$ & $89.26 \pm 1.77$ \\
\hline $\mathbf{5}$ & $97.45 \pm 1.30$ & $95.22 \pm 1.85$ & $90.22 \pm 1.97$ \\
\hline $\mathbf{5 S}$ & $93.56 \pm 2.13$ & $90.55 \pm 1.03$ & $88.77 \pm 2.01$ \\
\hline
\end{tabular}

Data was expressed as mean \pm SEM $(n=3)$. Cell viability was expressed as a percentage of the control value. $p<0.05$ was considered as statistically significant $\left({ }^{*} p<0.05,{ }^{* *} p<0.01,{ }^{* * *} p<0.001\right.$ vs control).

\section{Molecular Modeling Docking Studies}

To rationalize the mode of interaction and the impact of the absolute configuration, molecular modeling docking studies were performed. Figures $4 a-d$ show the result of the molecular modeling docking of $\mathbf{5 R}$ and $\mathbf{5} \boldsymbol{S}$ within the MAO-A active site. Analysis of the binding modes for the $\boldsymbol{R}$ isomer in the MAO-A active site cavity revealed that $\mathbf{5 R}$ is located in front of the FAD cofactor from re face. $\mathbf{5} \boldsymbol{R}$ interacts with the active site residues lining the cavity as well as the FAD cofactor effectively (Figure $4 a)\left(K_{i}=738.93 \mathrm{pM}\right)$. Two hydrogen bonds occur between the side chain amine hydrogens of Lys 305 and the methoxy moieties of the phenyl group of the inhibitor. An additional hydrogen bond forms between the carbonyl groups of the inhibitor and the cofactor FAD (green dashed-line in Figure 4c). In addition to these significant interactions, four $\pi-\pi$ interactions were identified between the side chain of Tyr407, Tyr444 and the benzoxazolinone ring of the inhibitor (pink dashed-line in Figure 4c). Also, in the 2D picture (Figure 4c) $5 \boldsymbol{R}$ enters various Van der Waals interactions with lle180, Asn181, Lys305, lleu335, Phe352, Tyr69, Gln215, Tyr197, Asp339, Lys218, Ala68, Gly67, Leu337, Phe208 and Gly443, amino acids.

As shown in Figure $4 \mathrm{~b}$, enantiomer $\mathbf{5 S}$ is located at the active site of MAO-A $\left(\mathrm{K}_{\mathrm{i}}=229.44\right.$ 
$n M)$. The 2-benzoxazolinone ring cannot make effective $\pi-\pi$ bonds with Tyr407 and Tyr444 since it cannot approach to FAD ring as in the case of $\mathbf{5} \boldsymbol{R}$ isomer. The 3,4-dimethoxyphenyl ring of $5 S$ makes one $\pi-\sigma$ interaction with Tyr197 and one $\pi-\pi$ with Tyr407. The phenyl ring at position 3 of the 2-pyrazoline ring makes two m-alkyl interactions with Leu335 and Ile180 and $\pi-\pi$ interaction with Phe208. Figures $4 b$ and $4 d$ show that the inhibitor enters several Van der Waals interactions with Asn181, Lys305, Ileu335, Phe352, Tyr69, Gly443 and Thr408 amino acids.

The experimental data given in Table $\mathbf{1}$ agree with these observations. All of the computational inhibition results support that the MAO-A inhibitory potency of the $\boldsymbol{R}$ enantiomer $\left(\mathrm{K}_{\mathrm{i}}=0.74 \times 10^{-3} \mu \mathrm{M}\right)$ is much higher and 310 times more selective in comparison to the $S$ enantiomer $\left(K_{i}=0.229 \mu M\right)$.

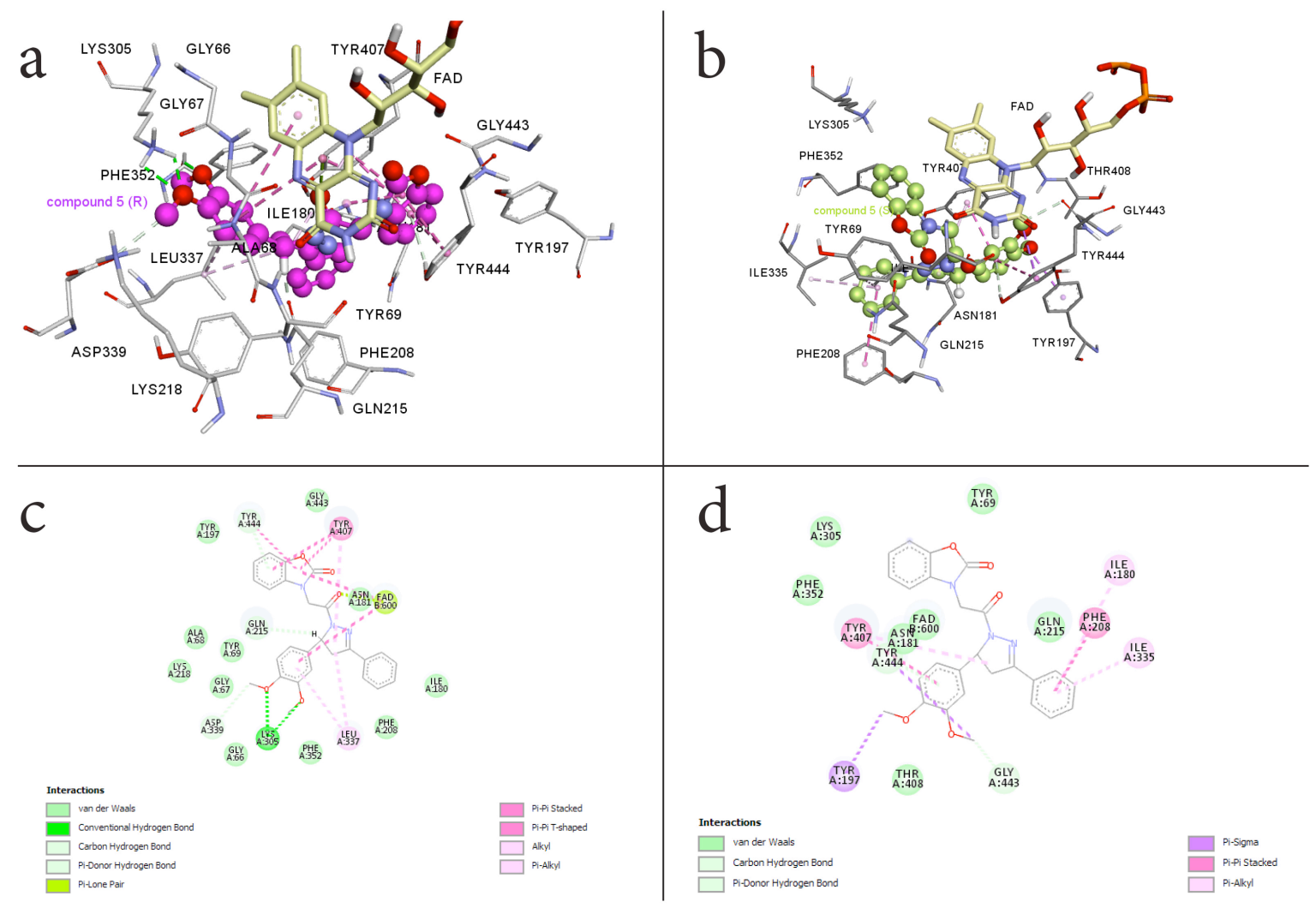

Figure 4. 3D representations of docked poses of the $5 R$ isomer (a) and the $5 S$ isomer (b) in the MAO-A active site. 2D interaction diagrams of the $5 R$ isomer (c) and the $5 S$ isomer (d) with amino acid residues lining the MAO-A active site. 


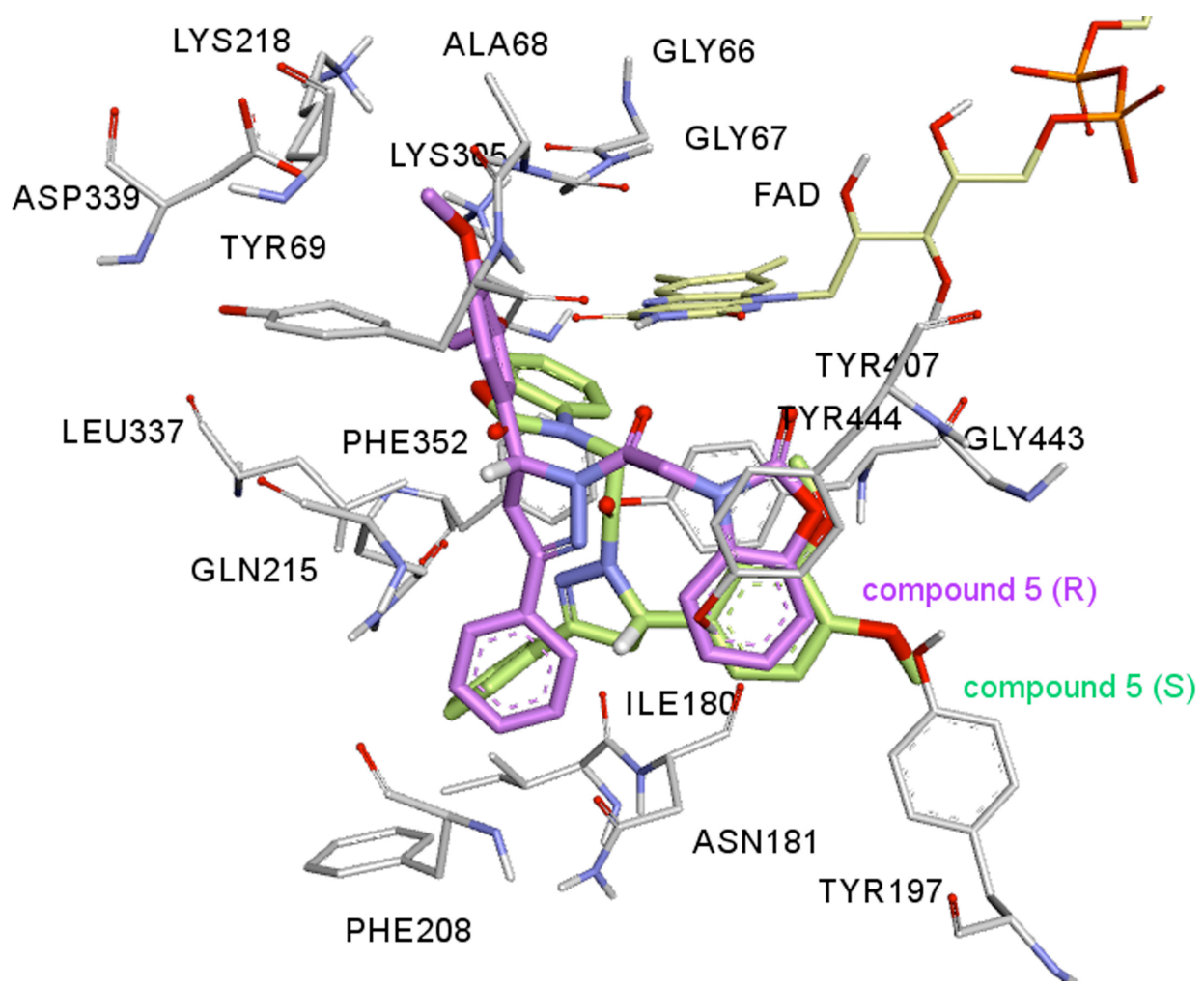

Figure 5. The $\mathbf{5} \boldsymbol{R}$ (magenta) and $\mathbf{5} \boldsymbol{S}$ (green) isomers superimposed within the active site of MAO-A isozyme. Chiral hydrogens are shown in white color, they are oriented differently in the active site of the enzyme.

In Figure $\mathbf{5} \mathbf{5 R}$ and $\mathbf{5 S}$ were superimposed within the MAO-A active site. As figure $\mathbf{5}$ shows, the benzoxazolinone ring of $\mathbf{5} \boldsymbol{R}$ orients itself in the hydrophobic cage surrounded by Tyr 407 , Tyr444 and the FAD cofactor making four $\pi-\pi$ interactions. In the case of $5 \mathbf{S}$, the 3,4dimethoxyphenyl ring of the $\mathbf{5 S}$ occupies the same volume of the hydrophobic cage making only one $\pi-\sigma$ interaction. The other moieties of the 4,5-dihydro-(1H)-pyrazole ring of both isomers do not overlap in the active site of the enzyme either. Having stereogenic center in $\mathbf{5}$ results in a very different binding mode and significant inhibition constant difference.

In Figure $\mathbf{5} \mathbf{5} \boldsymbol{R}$ and $\mathbf{5 S}$ were superimposed within the MAO-A active site. As figure $\mathbf{5}$ shows, the benzoxazolinone ring of $\mathbf{5} \boldsymbol{R}$ orients itself in the hydrophobic cage surrounded by Tyr407, Tyr444 and the FAD cofactor making four $\pi-\pi$ interactions. In the case of $5 \mathbf{S}$, the 3,4dimethoxyphenyl ring of the $\mathbf{5 S}$ occupies the same volume of the hydrophobic cage making only one $\pi-\sigma$ interaction. The other moieties of the 4,5-dihydro-(1H)-pyrazole ring of both isomers do not overlap in the active site of the enzyme either. Figure 4 (c and d) shows the interaction diagram reflected in $2 \mathrm{D}$ pictures. It was seen from the figure 5 , the chiral hydrogen of $\mathbf{5 R}$ makes a carbon hydrogen bond between the chiral hydrogen and $\mathrm{G} \ln 215$ amino acid residue, on the other hand this interaction is absent in $\mathbf{5 S}$ isomer. Having 
stereogenic center in $\mathbf{5}$ results in a very different binding mode and significant inhibition constant difference between $\mathrm{R}$ and $\mathrm{S}$ stereoisomer.

\section{CONCLUSION}

1-[2-(2-benzoxazolinone-3-yl)acetyl]-3-phenyl-5-(3,4-dimethoxyphenyl)-4,5-dihydro-(1H)pyrazole (5) was synthesized and separated by analytic and semipreparative HPLC technique and evaluated for in vitro inhibitory profiles of both enantiomers and the racemate towards hMAOs. Racemic 5 was found to inhibit hMAO-A selectively and competitively. According to the expectation that the chiral center may lead to different ligand enzyme interactions, the separate enantiomers were resubmitted to in vitro biological evaluation. Isolated enantiomers $\mathbf{5 R}$ and $\mathbf{5 S}$ were also found to be selective MAO-A inhibitors. The experimental selectivity index was found to be $2.35 \times 10^{-5}$ for $5 \boldsymbol{R}$ showing that this derivative is a highly selective and potent MAO-A inhibitor compared to moclobemide. A molecular modeling docking study was carried out using PDB enzymatic models in order to evaluate the molecular interactions of the enantiomers with hMAO isoforms. $\mathbf{5} \boldsymbol{R}$ appeared as the more potent and selective MAO-A inhibitor when compared to $\mathbf{5 S}$. This indicates that $\mathbf{5 R}$ interacts more strongly with the active site of MAO-A than $\mathbf{5 S}$. The key factor for the efficient and selective activity is, most probably, the shorter distance between $\mathbf{5} \boldsymbol{R}$ and the FAD ring at the active site of MAO.

In summary, the results show that seperated enantiomers of the the newly synthesized 4,5dihydro-(1H)-pyrazole derivative may be promising candidates as potent MAO-A inhibitor agents. These findings may assist medicinal chemists working in this area and in vivo studies on mice have recently been initiated.

\section{CONFLICTS OF INTEREST}

There are no conflicts of interest to declare.

\section{ACKNOWLEDGMENTS}

Funding by Scientific and Technological Research Council of Turkey (Project Number: 112T746) and by the Hacettepe University Research Fund (Project Number: 012D06301001 and 1527) is acknowledged. W.A.H and P.B. acknowledges support by the Fund for Scientific research FWO-Vlaanderen, and by BOF and IOF funding schemes.

\section{REFERENCES}

1. Westlund KN, Denney RM, Kochersperger LM, Rose RM. Distinct monoamine oxidase A and B populations in primate brain. Science (Washington, D. C., 1883-), 1985; 230(4722): 181-3. 
2. Westlund KN, Denney RM, Rose RM, Abell CW. Localization of distinct monoamine oxidase A and monoamine oxidase B cell populations in human brainstem. Neuroscience, 1988; 25(2): 439-56.

3. Ramsay RR, Albreht A. Kinetics, mechanism, and inhibition of monoamine oxidase. J. Neural Transm., 2018; https://doi.org/10.1007/s00702-018-1861-9.

4.. Bousquet $P$, Feldman $J$ and Schwartz J. Central cardiovascular effects of alpha adrenergic drugs: differences between catecholamines and imidazolines. J. Pharmacol. Exp. Ther., 1984; 230(1): 232-6.

5. Grimsby J, Lan NC, Neve R, Chen K, Shih JC. Tissue distribution of human monoamine oxidase A and B mRNA. J. Neurochem., 1990; 55(4): 1166-9.

6. Carradori, S. and Silvestri R. New Frontiers in Selective Human MAO-B Inhibitors. J. Med. Chem., 2015; 58(17): 6717-6732.

7. Kumar B, Sheetal A, Mantha K, Kumar V. Recent developments on the structure-activity relationship studies of MAO inhibitors and their role in different neurological disorders. RSC Adv., 2016; 6(48): 42660-42683.

8. Da Prada M, Kettler R, Keller HH, Cesura AM, Richards JG, Saura Marti J, MuggliManiglio D, Wyss PC, Kyburz E, Imhof RJ. From moclobemide to Ro 19-6327 and Ro 41-1049: the development of a new class of reversible, selective MAO-A and MAO-B inhibitors. J. Neural Trans. Suppl., 1990; 29: 279-92.

9. Mellick, GD, Buchanan DD, McCann SJ, James KM, Johnson AG, Davis D R, Liyou N, Chan D, Le Couteur DG. Variations in the monoamine oxidase $B$ (MAOB) gene are associated with Parkinson's disease. Mov. Disord., 1999; 14(2): 219-24.

10. Drukarch B and van Muiswinkel FL. Drug treatment of Parkinson's disease Time for phase II. Biochem. Pharmacol., 2000; 59(9): 1023-1031.

11. Carreiras MC and Marco JL. Recent approaches to novel anti-Alzheimer therapy. Curr. Pharm. Des, 2004; 10(25): 3167-3175.

12. Riederer $P$, Lachenmayer $L$ and Laux G. Clinical applications of MAO-Inhibitors. Curr. Med. Chem, 2004; 11(15): 2033-2043.

13. Guay DR. Rasagiline (TVP-1012): a new selective monoamine oxidase inhibitor for Parkinson's disease, Am. J. Geriatr. Pharmacother, 2006; 4(4): 330-346.

14. Youdim $\mathrm{MBH}$, Edmondson $\mathrm{D}$ and Tipton KF. The therapeutic potential of monoamine oxidase inhibitors. Nat. Rev. Neurosci, 2006; 7(4): 295-309.

15. Bortolato $M$, Chen $K$ and Shih JC. Monoamine oxidase inactivation: From pathophysiology to therapeutics. Adv. Drug Delivery Rev, 2008; 60(13-14): 1527-1533.

16. Coutts RT, Baker GB and Danielson TJ. New developments in monoamine oxidase inhibitors, Developments of Drug and Modern Medicines Part I. Drug Design, 1986; (p. 40-48). Chichester: Ellis Horwood Ltd.

17 Erol Gunal S, Teke Tuncel S, Gokhan Kelekci N, Ucar G, Yuce Dursun B, Sag Erdem $\mathrm{S}$, Dogan I. Asymmetric synthesis, molecular modeling and biological evaluation of 5methyl-3-aryloxazolidine-2,4-dione enantiomers as monoamine oxidase (MAO) inhibitors Bioorg. Chem. 2018, 77, 608-618.

18. Binda C, Wang J, Pisani L, Caccia C, Carotti A, Salvati P. et al Structures of Human Monoamine Oxidase B Complexes with Selective Noncovalent Inhibitors: Safinamide and Coumarin Analogs, J. Med. Chem., 2007; 50: 5848-5852.

19. Itoh K, Hoshino K, Endo A, Asakawa T, Yamakami K. Noji C, Kosaka T, Tanaka Y. Chiral inversion of RS-8359: a selective and reversible MAO-A inhibitor via oxidoreduction of keto-alcohol. Chirality, 2006; 18(9): 698-706.

20. Dar A, Khan KM, Ateeq HS, Khan S, Rahat S, Perveen S, Supuran CT. Inhibition of monoamine oxidase-A activity in rat brain by synthetic hydrazines: Structure-activity relationship (SAR). J. Enzyme Inhib. Med. Chem., 2005; 20(3): 269-274.

21. Wouters J, Ooms F, Jegham S, Koenig JJ, George P, Durant F. Reversible Inhibion of Type B Monoamine Oxidase. Theoretical Study of Model Diazo Heterocyclic Compounds Eur. J. Med. Chem., 1997; 32: 721-730. 
22. Altomare C, Cellamare S, Summo L, Catto M, Carotti A, Thull U, et al. Inhibition of Monoamine Oxidase-B by Condensed Pyridazines and Pyrimidines: Effects of Lipophilicity and Structure-Activity Relationships, J. Med. Chem, 1998; 41, 3812-3820.

23. Binda C, Wang J, Li M, Hubálek F, Mattevi A, Edmondson DE. Structural and Mechanistic Studies of Arylalkylhydrazine Inhibition of Human Monoamine Oxidases A and B. Biochemistry, 2008; 47(20): 5616-5625.

24. Parmar SS, Pandey BR, Dwivedi C, Harbison RD. Anticonvulsant activity and monoamine oxidase inhibitory properties of 1,3,5-trisubstituted pyrazolines. J. Pharm. Sci., 1974; 63(7): 1152-5.

25. Soni N, . Pande R, Kalsi TK, Gupta SS, Parmar JP. Inhibition of rat brain monoamine oxidase and succinic dehydrogenase by anticonvulsant pyrazolines. Res. Commun. Chem. Pathol. Pharmacol., 1987; 56(1): 129-32.

26. Yesilada A, Gokhan N, Ozer I, Vural K, Erol K. 5-Methyl-8-N-substituted-thiocarbamoyl7,8-diazabicyclo[4.3.0]non-6-enes: evaluation as BSAO inhibitors and pharmacological activity screening. Farmaco, 1996; 51(12): 775-780.

27. Manna F, Chimenti F, Bolasco A, Bizzarri B, Befani O, Pietrangeli $P$, Mondovi B, Turini $P$. Inhibitory effect of 1,3,5-triphenyl-4,5-dihydro-(1H)-pyrazole derivatives on activity of amine oxidases. J. Enzyme Inhib., 1998; 13(3): 207-216.

28. Manna F, Chimenti F, Bolasco A, Secci D, Bizzarri B, Befani O, Turini P, Mondovi B, Alcaro S, Tafi A. Inhibition of amine oxidases activity by 1-acetyl-3,5-diphenyl-4,5dihydro-(1H)-pyrazole derivatives. Bioorg. Med. Chem. Lett., 2002; 12(24): 3629-3633.

29. Gokhan N, Yesilada A, Ucar G, K Erol A, Bilgin A. 1-N-substituted thiocarbamoyl-3phenyl-5-thienyl-2-pyrazolines: Synthesis and evaluation as MAO inhibitors. Arch. Pharm. (Weinheim, Ger.), 2003; 336(8): 362-371.

30. Chimenti F, Bolasco A, Manna F, Secci D, Chimenti $P$, Befani O, Turini $P$, Giovannini V, Mondovi B, Cirilli R, La Torre F. Synthesis and Selective Inhibitory Activity of 1-Acetyl3,5-diphenyl-4,5-dihydro-(1H)-pyrazole Derivatives against Monoamine Oxidase. J. Med. Chem., 2004; 47(8): 2071-2074.

31. Chimenti F, Maccioni E, Secci D, Bolasco A, Chimenti P, Granese A, Befani O, Turini P, Alcaro S, Ortuso F, Cirilli R, La Torre F, Cardia MC, Distinto S. Synthesis, molecular modeling studies, and selective inhibitory activity against monoamine oxidase of 1thiocarbamoyl-3,5-diaryl-4,5-dihydro-(1H)- pyrazole derivatives. J. Med. Chem., 2005; 48(23): 7113-7122.

32. Ucar G, Gokhan N, Yesilada A, Yabanoglu S, Bilgin A A. Interaction of some 1-NSubstituted thiocarbamoyl-3-phenyl-5-thienyl-2-pyrazolines with rat liver semicarbazidesensitive amine oxidase (SSAO), Hacettepe Univ. J. Fac. Pharm., 2005; 25, 23-34.

33. Gokhan-Kelekci N, Yabanoglu S, Kupeli E, Salgin-Goksen U, Ozgen O, Ucar G, Yesilada E, Kendi E, Yesilada A, Bilgin AA. A new therapeutic approach in Alzheimer disease: Some novel pyrazole derivatives as dual MAO-B inhibitors and antiinflammatory analgesics. Bioorg. Med. Chem., 2007; 15(17): 5775-5786.

34. Yabanoglu S, Ucar G, Gokhan N, Salgin U, Yesilada A, Bilgin AA. Interaction of rat lung SSAO with the novel 1-N-substituted thiocarbamoyl-3-substituted phenyl-5-(2-pyrolyl)-2pyrazoline derivatives. J. Neural Transm., 2007; 114(6): 769-773.

35. Milcent R, Akhnazarian A and Lensen N. Synthesis of 1-(2-hydroxyphenyl)-2,4imidazolidinedione derivatives through cyclic transformations of ethyl 2-oxo-3 $(2 \mathrm{H})$ benzoxazoleacetate derivatives. J. Heterocycl. Chem., 1996; 33(6): 1829-1833.

36. Cakir B, Dag O, Yildirim E, Erol K, Sahin MF. Synthesis and anticonvulsant activity of some hydrazones of 2[(3H)-oxobenzoxazolin-3-yl-aceto]hydrazide. J. Fac. Pharm. Gazi Univ., 2001; 18(2): 99-106.

37. Salgin-Goksen U, Gokhan-Kelekci N, Goktas O, Koysal Y, Kiliç E, Isik S, Aktay G, Ozalp M. 1-Acylthiosemicarbazides, 1,2,4-triazole-5(4H)-thiones, 1,3,4-thiadiazoles and hydrazones containing 5-methyl-2-benzoxazolinones: Synthesis, analgesic, antiinflammatory and antimicrobial activities. Bioorg. Med. Chem., 2007; 15(17): 5738-5751.

38. Davey W and Tivey DJ. Chalcones and related compounds. IV. Addition of hydrogen cyanide to chalcones. J. Chem. Soc., 1958; p. 1230-6. 
39. Dickinson R, Heilbron IM and Irving F. Intermolecular condensation of styryl methyl ketones. J. Chem. Soc., 1927: p. 1888-97.

40. Sahin ZS, Salgin-Goksen U, Gokhan-Kelekci N, Isik S. Synthesis, crystal structures and DFT studies of 1-[2-(5-methyl-2-benzoxazolinone-3-yl)acetyl]-3-phenyl-5-(3,4dimethoxyphenyl)-4,5-dihydro-1H-pyrazole and 1-[2-(5-chloro-2-benzoxazolinone-3yl)acetyl]-3-phenyl-5-(4-methoxyphenyl)-4,5-dihydro-1H-pyrazole. J. Mol. Struct., 2011; 1006(1-3): 147-158.

41. Gokhan-Kelekci N, Koyunoglu S, Yabanoglu S, Yelekci K, Ozgen O, Ucar G, Erol E, Kendi E, Yesilada A. New pyrazoline bearing 4(3H)-quinazolinone inhibitors of monoamine oxidase: Synthesis, biological evaluation, and structural determinants of MAO-A and MAO-B selectivity. Bioorg. Med. Chem., 2009; 17(2): 675-689.

42. Halgren TA, MMFF VII. Characterization of MMFF94, MMFF94s, and other widely available force fields for conformational energies and for intermolecular-interaction energies and geometries. J. Comput. Chem., 1999; 20(7): 730-748.

43. Halgren TA. Merck molecular force field. I. Basis, form, scope, parameterization, and performance of MMFF94. J. Comput. Chem., 1996; 17(5 \& 6): 490-519.

44. Clark M, Cramer RD and Van Opdenbosch N. Validation of the general purpose Tripos 5.2 force field. J. Comput. Chem., 1989; 10(8): 982-1012.

45. Spartan'08. Wavefunction, Inc., 2008.CONFLEX Program. Conflex Corporation,Tokyo.

46. Goto $\mathrm{H}$ and Osawa $\mathrm{E}$. Corner flapping: a simple and fast algorithm for exhaustive generation of ring conformations. J. Am. Chem. Soc., 1989; 111(24): 8950-1.

47. Goto H, Osawa E. Viewpoint 11 - approaches to the global minimum, J. Mol.Struc. 1993; 285, 157-168.

48. Gaussian 09, Revision C.01, M. J. Frisch, G. W. Trucks, H. B. Schlegel, G. E. Scuseria, M. A. Robb, J. R. Cheeseman, G. Scalmani, V. Barone, B. Mennucci, G. A. Petersson, H. Nakatsuji, M. Caricato, X. Li, H. P. Hratchian, A. F. Izmaylov, J. Bloino, G. Zheng, J. L. Sonnenberg, M. Hada, M. Ehara, K. Toyota, R. Fukuda, J. Hasegawa, M. Ishida, T. Nakajima, Y. Honda, O. Kitao, H. Nakai, T. Vreven, J. A. Montgomery, Jr., J. E. Peralta, F. Ogliaro, M. Bearpark, J. J. Heyd, E. Brothers, K. N. Kudin, V. N. Staroverov, R. Kobayashi, J. Normand, K. Raghavachari, A. Rendell, J. C. Burant, S. S. Iyengar, J. Tomasi, M. Cossi, N. Rega, J. M. Millam, M. Klene, J. E. Knox, J. B. Cross, V. Bakken, C. Adamo, J. Jaramillo, R. Gomperts, R. E. Stratmann, O. Yazyev, A. J. Austin, R. Cammi, C. Pomelli, J. W. Ochterski, R. L. Martin, K. Morokuma, V. G. Zakrzewski, G. A. Voth, P. Salvador, J. J. Dannenberg, S. Dapprich, A. D. Daniels, Ö. Farkas, J. B. Foresman, J. V. Ortiz, J. Cioslowski, and D. J. Fox, Gaussian, Inc., Wallingford CT, 2009.

49. Yanez M, Fraiz N, Cano E, Orallo F. Inhibitory effects of cis- and trans-resveratrol on noradrenaline and 5-hydroxytryptamine uptake and on monoamine oxidase activity. Biochem. Biophys. Res. Commun., 2006; 344(2): 688-695.

50. Chimenti F, Maccioni E, Secci D, Bolasco A, Chimenti P, et al. Synthesis, Stereochemical Identification, and Selective Inhibitory Activity against Human Monoamine Oxidase-B of 2-Methylcyclohexylidene-(4-arylthiazol-2-yl)hydrazones. $J$. Med. Chem., 2008; 51(16): 4874-4880.

51. Anderson MC, Hasan F, McCrodden JM, Tipton KF. Monoamine oxidase inhibitors and the cheese effect. Neurochem. Res., 1993; 18(11): 1145-9.

52. Bradford MM. A rapid and sensitive method for the quantitation of microgram quantities of protein utilizing the principle of protein-dye binding. Anal. Biochem., 1976; 72(1-2): 248-54.

53. Petzer A, Pienaar A and Petzer JP. The interactions of caffeine with monoamine oxidase. Life Sci., 2013; 93(7): 283-287.

54. Mathew B, Haridas A, Uçar G, Baysal I, et. al. Exploration of chlorinated thienyl chalcones: A new class of monoamine oxidase-B inhibitors. Int. J. Biol. Macromol., 2016; 91: $680-695$. 
55. Wu CF, Bertorelli R, Sacconi M, Pepeu G, Consolo S. Decrease of brain acetylcholine release in aging freely-moving rats detected by microdialysis. Neurobiol. Aging, 1988; 9(4): 357-61.

56. Son S.-Y, Ma J, Kondou Y, Yoshimura M, Yamashita E, Tsukihara T, et al. Structure of human monoamine oxidase $A$ at $2.2-\AA$ resolution: The control of opening the entry for substrates/inhibitors. Proc. Natl. Acad. Sci. U. S. A., 2008; 105(15): 5739-5744.

57. Binda C, Wang J, Pisani L, Caccia C, Carotti A, Salvati P, Edmondson DE, Mattevi A. Structures of Human Monoamine Oxidase B Complexes with Selective Noncovalent Inhibitors: Safinamide and Coumarin Analogs. J. Med. Chem., 2007; 50(23): 5848-5852.

58. Mayo SL, Olafson BD and Goddard WA. DREIDING: a generic force field for molecular simulations. J. Phys. Chem., 1990; 94(26): 8897-909.

59. Morris GM, Huey R, Lindstrom W, Sanner MF, Belew RK, Goodsell DS, Olson AJ. AutoDock and AutoDockTools: Automated docking with selective receptor flexibility. J. Comput. Chem., 2009; 30(16): 2785-2791.

60. Yelekci K, Karahan $\mathrm{O}$ and Toprakci M. Docking of novel reversible monoamine oxidase$B$ inhibitors: Efficient prediction of ligand binding sites and estimation of inhibitors thermodynamic properties. J. Neural Transm., 2007; 114(6): 725-732.

61. Akdogan ED, Erman B and Yelekci K. In silico design of novel and highly selective lysine-specific histone demethylase inhibitors. Turk. J. Chem., 2011; 35(4): 523-542.

62. FDA's Policy Statement for the Development of New Stereoisomeric Drugs, Chirality, 4, 338-340, (1992).

63. Triggle DJ. Stereoselectivity of drug action, Drug Discovery Today, 1997, 2(4), 138-147.

64. Simonyi M. On chiral drug action, Medicinal Research Reviews, 1984, 4(3), 359-413.

65. Patel, BK. Hutt AJ. Stereoselectivity in drug action and disposition: an overview. In: Reddy IK, Mehvar R, ed. Chirality in Drug Design and Development. Caplus, 2004: 139-190.

66. Berova N, Nakanishi K, Woody RW, eds Circular Dichroism: Principles and Applications. 2000: Wiley-VCH. 877 pp.

67. Freedman TB, Cao X, Dukor RK, Nafie LA. Absolute configuration determination of chiral molecules in the solution state using vibrational circular dichroism, Chirality, 2003; 15 (9): 743-758.

68. Polavarapu PL, Covington CL. Comparison of Experimental and Calculated Chiroptical Spectra for Chiral Molecular Structure Determination. Chirality, 2014; 26: 539-552.

69. Debie E, De Gussem E, Dukor RK, Herrebout W, Nafie LA, Bultinck P. A confidence level algorithm for the determination of absolute configuration using vibrational circular dichroism or Raman optical activity. ChemPhysChem, 2011; 12(8): 1542-1549.

70. Petzer JP and Petzer A. Leflunomide, a Reversible Monoamine Oxidase Inhibitor. Cent. Nerv. Syst. Agents Med. Chem., 2016; 16(2): 112-119. 